\title{
Moringa Oleifera Tea Alters Neutrophil but not Lymphocyte Levels in Blood of Acutely Stressed Mice
}

\author{
Glenn E Drue ${ }^{1}$, Steven Hurley ${ }^{2}$ and Radiah C Minor ${ }^{2 \star}$ \\ ${ }^{1}$ Animal Facilities, University at Buffalo, 12 Capen Hall Buffalo, USA \\ ${ }^{2}$ Associate Professor, Department of Animal Sciences, College of Agriculture and Environmental Sciences, North Carolina Agricultural and \\ Technical State, University, 1601 E. Market St. Greensboro, USA
}

\section{Article Info}

\section{*Corresponding author:}

Radiah C Minor

Department of Animal Sciences, North Carolina Agricultural and Technical State University, Greensboro, NC, 27411, USA

Phone: (336) 285-4787

Fax: (336) 334-7288

E-mail: rcminor@ncat.edu

\section{Received: May 26, 2018}

Accepted: May 29, 2018

Published: June 5, 2018

Citation: Drue Jr GE, Hurley S, Minor RC. Moringa Oleifera Tea Alters Neutrophil but not Lymphocyte Levels in Blood of Acutely Stressed Mice. Madridge J Immunol. 2018; 2(1): 43-48.

doi: $10.18689 / \mathrm{mjim}-1000110$

Copyright: (c) 2018 The Author(s). This work is licensed under a Creative Commons Attribution 4.0 International License, which permits unrestricted use, distribution, and reproduction in any medium, provided the original work is properly cited.

Published by Madridge Publishers

\begin{abstract}
Stress influences health and wellbeing, altering many physiological systems including the immune system. Herbal concoctions including teas impact immunity and mitigate the negative effects of stress. Moringa oleifera is a tree that is exceptionally rich in medicinally relevant and immune modulating nutrients and phytochemicals. The goal of this experiment was to determine whether tea prepared from dried Moringa oleifera leaves influenced acute stress induced changes to the levels of circulating lymphocyte and neutrophils. Balb/c mice were offered either water or Moringa tea ad libitum for four days and then randomly selected for either restraint for $1 \mathrm{~h}$ or $12 \mathrm{~h}$ to induce stress or left alone (unstressed). Post stress the levels of circulating neutrophils and lymphocytesin the blood were determined by differential cell staining. While, mice that consumed water had significant $(p<0.05)$ increases in circulating blood neutrophils after $1 \mathrm{~h}$ of restraint, the level of neutrophils in the mice dosed with tea remained unchanged. Post $12 \mathrm{~h}$ of restraint stress significant $(p<0.05)$ increases in neutrophil levels were observed in mice that consumed tea but not in mice that consumed water. In the case of lymphocytes, consumption of Moringa tea had no effect. Compared to unstressed mice, $1 \mathrm{~h}$ or $12 \mathrm{~h}$ of restraint stress resulted insignificant $(p<0.05)$ decreases in circulating lymphocytes of similar magnitude in both the water and Moringa tea groups. Flow cytometric analysis showed no significant differences in CD3 + T cells or CD19+ B cells levels. These data suggest that consumption of the Moringa tea can influence stress induced variations to circulating neutrophils but not lymphocytes.
\end{abstract}

Keywords: Stress; Immunomodulation; Lymphocytes; Neutrophils; Moringa oleifera.

\section{Introduction}

Stress causes changes to many physiological systems [1]. Within the immune system stress causes changes to immune cell production, circulation, tissue residency, and function and depending on the duration of the stress either positive or deleterious effects can occur [2-6]. Chronic stress for example, leads to decreases in both circulating neutrophils and lymphocytes and is generally thought to be suppressive to immune responses, but is also associated with inflammation [7], [8]. In contrast, acute, fight-orflight stress is characterized by increased levels of circulating blood neutrophils and decreased circulating lymphocytes [6]. This redistribution of cells allows for quick responses that protect the host. This is particularly relevant during fight-or-flight situations when high levels of blood circulating neutrophils are critical for quickly responding to potential microorganism exposure that could occuras a result of injury [3], [9]. 
Second only to water, tea is the most widely consumed beverage in the world and approximately $80 \%$ of US households consume tea [10]. Having high levels of phytochemicals and nutrients, teas have health promoting properties [11]; including antioxidant, anti-cancer [12], anti-inflammatory and immunomodulating properties. Tea consumption has also been associated with stress relief with both green and black teas having positive impacts on psychological stress and stress recovery [13], [14].

The Moringa oleifera tree (Family: Moringaceae) is a perennial softwood tree also known as the drumstick or horseradish tree. It is native to the sub-Himalayan regions of India, Pakistan, Bangladesh and Afghanistan, but is also cultivated in Africa, the Caribbean, and southern regions of the United States [15], [16]. All parts of the Moringa tree (seeds, pods, flowers, leaves, roots and stems) are edible and have long been consumed by humans and animals because of its high nutritional value, various health, and medicinal properties [16-19]. Moringa is rich in phyto-chemicals, antioxidants, vitamins/minerals, and proteins and holds antitumor, anticancer, anti-tensive, anti-inflammatory, and antibacterial properties [15].

Because of its medicinal properties, Moringa leaf tea is touted as a "super tea" and much like leaf powders, oils and alcoholic extracts, has immune modulating capacity. Previous studies from our lab, using a mouse model of acute lung inflammation, showed that mice that consumed tea prepared from dried Moringa leaves had decreased lung inflammation marked by alterations in cytokine production, leukocyte migration, and neutrophil apoptosis [20]. Several studies using animal models show that Moringa extracts impact hematological parameters. Auwal, et al for example, demonstrated that providing aqueous extracts prepared from Moringa seeds to wistar rats lead to significant increases in blood levels of neutrophils and other granulocytes, but significant decreases in lymphocytes [21]. However, in another study rats that consumed high doses of $\mathrm{M}$. oleifera leaf extracts had significantly higher lymphocyte and lower neutrophil levels in blood as compared to controls [22]. This is in contrast to a study by Gupta et al showing that mice dosed with ethanolic M. oleifera leaf extracts, for 15 days, had dose dependent increases in total white blood cell counts and percent neutrophils. Furthermore, in that study, the Moringa extracts reversed cyclophosphamide induced immunosuppression of neutrophils [23]. These data suggest that consumption of extracts from Moringa can lead to alterations in levels of circulating blood neutrophils and lymphocytes, but the effect that Moringa, more specifically Moringa tea, has on stress induce changes to circulating blood leukocytes has not been reported. The current study investigatedthe immunomodulatory activity of $M$. oleifera leaf tea during acute stress. Focusing specifically on stress induced changes to blood circulating lymphocytes and neutrophils.

\section{Material and Methods}

Animals: All animal handling and experimental procedures for this study were conducted in accordance with applicable regulations and were approved by the Institutional Animal Care and Use Committee of North Carolina A\&T State University. For this study a total of 48 female Balb/c mice between the ages of 5 to 7 weeks were purchased from Harlan Laboratory (Indianapolis, Indiana). Mice were maintained in the Laboratory Animal Resource Unit of North Carolina A\&T State University on a 12 light/12 dark cycle and consistent temperature (68-70 $\mathrm{F}$ ) and humidity (58-60\%). During the 5-day dosing period, all mice had ad libitum access to food and liquid (water or tea) and were minimally handled daily to record weights.

Preparation of $1 \%(w / v)$ Moringa Tea and Dosing. Moringa tea was prepared as previously described in McKnight, et al 2014 [20]. Briefly, approximately 50g of dried Moringa oleifera leaves were steeped in $5 \mathrm{~L}$ of $95^{\circ} \mathrm{C}$ distilled water for 30 minutes. The resulting tea was poured through sterile cheese cloth into sterile beakers to filter out leaves and large particles. Smaller particles were removed by filtering the tea further through a $3 \mathrm{M}$ filter paper lined funnel into a vacuum flask. Finally, the tea was filtered through a sterile $0.22 \mu \mathrm{M}$ PES vacuum filter system (Cell treat, Largo FL). Sterile filtered tea was aliquoted into sterile $50 \mathrm{ml}$ conical tubes under a laminar flow hood and stored at $4^{\circ} \mathrm{C}$ until used. For Moringa tea dosing, mice were randomly divided into either the water $(n=24)$ or Moringa tea groups $(n=24)$. Every morning for four 24-hour periods (beginning Monday a.m. and ending Friday a.m.), 100ml of fresh distilled water (control) or Moringa tea (tea) was provided. Consumption of the water or tea was monitored daily by determining the amount of liquid remaining from the amount of liquid offered $(100 \mathrm{ml})$. The average daily consumption per mouse was determined by dividing the total water consumption of each cage by the number of mice per cage. In addition, mouse weight and chow consumption were recorded daily.

Induction of Stress: For this study two trials were completed. For trial 1 stress was induced for 1-hour and for trial 2, 12-hours. Both trials were performed twice with 12 mice in each replicate for a total of 24 mice in each trial. Mice $(n=12)$ in eachtrial replicates were divided into four treatment groups $(n=3)$ as follows: (1) water/no stress, (2) water/ + stress (3) Moringa tea/ no stress, and (4) Moringa tea/ + stress. On the morning of day four, three mice each from dosing condition groups (water or tea) were randomly selected and stressed using the physical restraint method as described in Yin et al, 2000 [7]. Briefly, mice were placed into $50 \mathrm{ml}$ conical polyethylene tubes; for $1 \mathrm{~h}$ (9:00am-10:00am) in trial 1 or 12 hours $(6: 00 \mathrm{am}-6: 00 \mathrm{pm})$ in trial 2. While tubes restricted overall movement, several holes were placed in the body of the tube to provide adequate ventilation and one hole placed in the cap to allow for free movement of the tail. Once restrained in the tubes, mice were placed horizontally in their cages. Quiet conditions were provided for both the control (non-stressed) and stressed groups for the entire restraint periods. Neither the experimental nor the control animals had access to food or water during the restraint period.

Blood Collection and Cell Analysis. Immediately following the $1 \mathrm{~h}$ or $12 \mathrm{~h}$ stress period, mice in the stressed and nonstressed groups were sacrificed with Isoflurane (Baxter, 
Deerfield, IL). Approximately 200-500ul of whole blood was collected via terminal cardiac puncture. Blood was transferred to micro centrifuge tubes containing $50 \mu \mathrm{l}$ of $0.5 \mathrm{M}$ EDTA to prevent coagulation and smeared in slides for analysis by differential cell staining as described in (Corn Minor, et al 2010). [24]. Briefly, 2-5 $\mathrm{ml}$ of the freshly collected blood was smeared onto glass slides. The smeared slides were dried, fixed, and stained using HEMA 3 Stain Set (Fisher Scientific, Pittsburg, PA). Cells were identified and counted based on color and morphology using a compound light microscope with a 100x oil immersion lens. A minimum of 100 total cells per slide was counted. Blood was also processed for flow cytometric lymphocyte phenotyping. Blood was incubated with $1 \mathrm{X}$ multispecies red blood cell (RBC) lysis buffer (eBioscience, San Diego, $C A$ ) for $5 \mathrm{~min}$ at room temp. The cell pellets were washed by centrifuging for $5 \mathrm{~min}$ at 1000 RPM. Resuspended cells were incubated with Fc block (rat IgG2b anti-mouse CD16/CD32 monoclonal antibody (BD Biosciences) then stained with antiCD3 FITC (BD Biosciences) and anti-CD19 APC for 30 min at room temperature in the dark. Cells were washed two times with FACS buffer (Phosphate buffered saline with 10\% Fetal Bovine Serum and $0.1 \%$ NaN3 sodium azide), fixed with $1 \%$ paraformaldehyde, washed, and finally resuspended in FACS buffer. Cells were acquired with an Accuri C6 Flow Cytometer (BD Biosciences, San Jose, CA) collecting 10,000 total events.

\section{Statistical Analysis}

Graph Pad Prism version 5 (La Jolla, CA) was used to create graphs and perform statistical analysis. A completely randomized one-way ANOVA with Bonferroni post hoc tests was used to perform statistical analysis on differential cell staining counts and flow cytometry. Paired student $\mathrm{t}$-test was used to determine significance on weight and feed/water/tea consumption data. P values less than 0.05 were considered significant.

\section{Results}

Moringa Tea Consumption. During the dosing period all mice had free access to feed, and either water or tea for four -24hour periods (4 days). Consistent with our previously reported findings [20]. Mice in this study consumed Moringa tea at the same or at higher rate than water (Figure 1A). There were no significant differences in feed consumption or weight between the water or tea groups during the 4-day dosing period (Figure 1B and C).

Stressed Induced Changes in Circulating Neutrophils Are Altered by Consumption of Moringa Tea. To determine the effect Moringa tea consumption has on stress induced immunomodulation, mice in the water or Moringa tea groups were placed in stressed or unstressed conditions. Acute stress is shown to lead to increases in circulating neutrophils. In this study mice that drank water and were exposed to 1 hour of stress had significant increases in circulating neutrophils as expected. However, no change in the level of circulating neutrophils was observed in mice that consumed Moringa tea (Figure 2A). With more prolonged stress (12 hours), the
Moringa tea group showed significantly higher levels of blood circulating neutrophils as compared to their non-stressed counterparts (Figure 2B).In contrast, stress had no effect on the level of circulating neutrophils in mice that consumed water (Figure 2B). Together these data suggest that Moringa tea modulates the impact of stress on neutrophils; abrogating the changes induced by 1 hour of stress but enhancing that of longer stress induction.

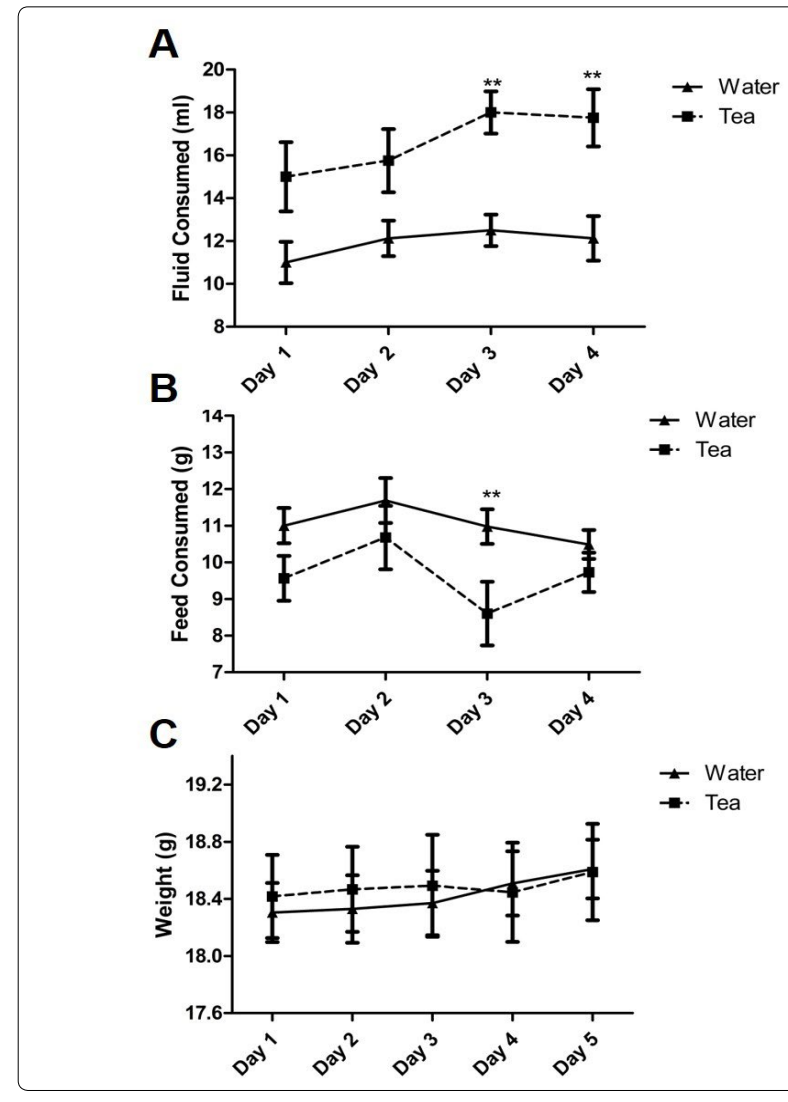

Figure 1. Mice were offered water $(\mathbf{\Lambda})$ or Moringa tea $(\boldsymbol{\square})$ for 4 day ad libitum. Average (A) fluid intake (B) feed consumption and (C) weight gain over 4- (24) hour (day) periods was calculated. Data are an average of $(n=12) .\left({ }^{* *} P<0.05\right)$

Moringa Tea Does Not Impact Stress Induced Modulation of Lymphocytes. One hour of restraint stress in mice causes increases in blood neutrophils and decreases circulating lymphocytes [4]. For this study, one hour of stress resulted in significant decreases in circulating blood lymphocytes when compared to their unstressed counterparts in both the water and the Moringa tea groups. No significant differences between the dosing groups (water vs. tea) were observed (Figure 3A). Similar results were found when mice underwent 12-hours of restraint stress (Figure 3B). Flow cytometry was used to determine if there were specific changes to the percentages of $\mathrm{T}$ and $\mathrm{B}$-cells that could not be detected with differential cell staining. No significant changes in the percent of circulating $T(C D 3+)$ or $B(C D 19+)$ cells after stress in either the water or tea groups were observed (Figure $4 \mathbf{A}$ and $\mathbf{B}$ ). This suggests that Moringa tea does not affect stress induced modulation of lymphocytes within the blood. 

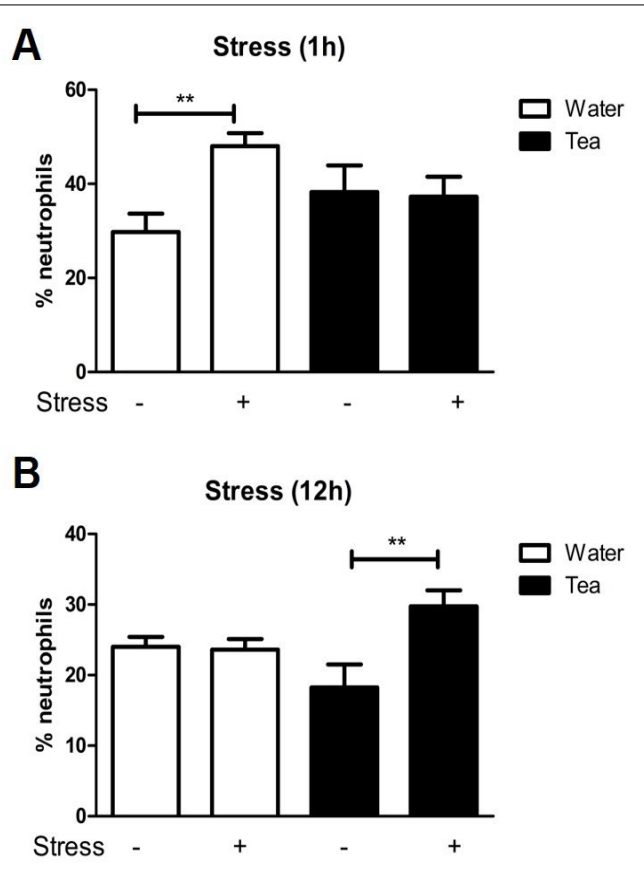

Figure 2. Mice were dosed with water (open bars) or Moringa tea (closed bars) for 4 days. On the fifth day mice were either left alone (- stress) or restrained for 1 hour (A) or 12 hours (B) to induce stress (+ stress). The percent of blood circulating neutrophils was determined by differential cell staining. Data is an average of $n=6$ mice in each treatment groups. $(* * \mathrm{P}<0.05)$
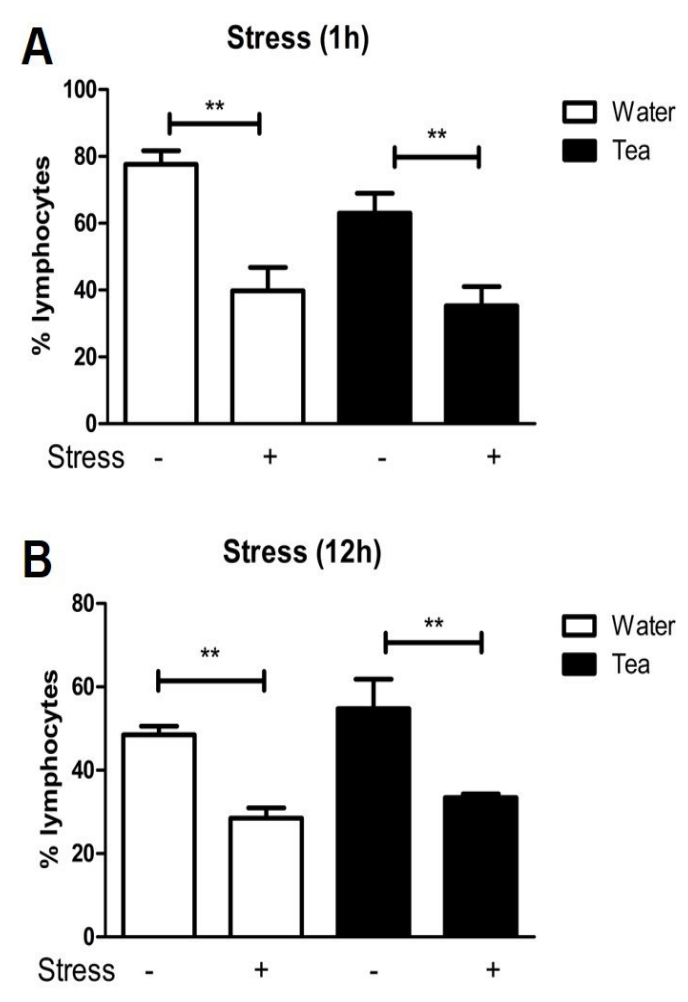

Figure 3. Mice were dosed with water (open bars) or Moringa tea (closed bars) for 4 days. On the fifth day mice were either left alone

(- stress) or restrained for 1 hour (A) or 12 hours (B) to induce stress (+ stress). The percent of blood circulating lymphocytes was determined by differential cell staining. Data is an average of $n=6$ mice in each treatment groups. $\left({ }^{* *} \mathrm{P}<0.05\right.$

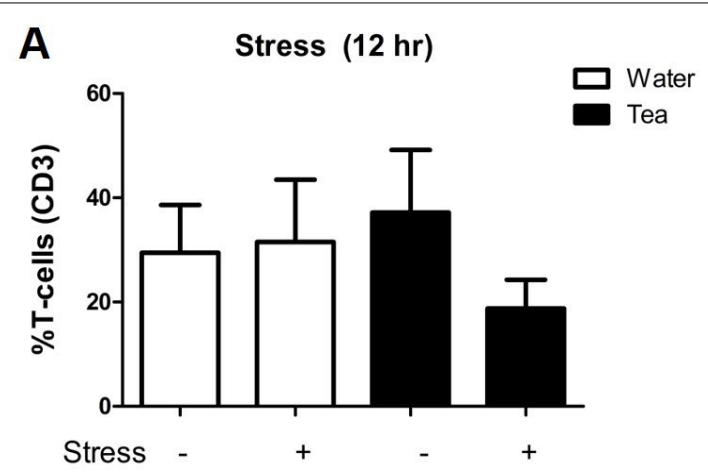

B

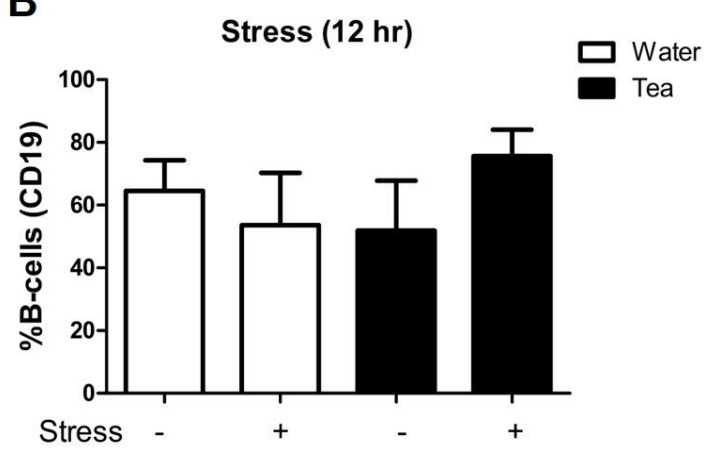

Figure 4. Mice were dosed with water (open bars) or Moringa tea (closed bars) for 4 days. On the fifth day mice were either left alone (- stress) or restrained for 12 hours (B) to induce stress (+ stress). The percent of blood circulating T-cellsCD4+ $(\mathbf{A})$ and $B$ cells CD19+ (B) was determined by flow cytometry. Data is an average of $n=3$ mice in each treatment groups.

\section{Discussion}

For decades, plant-based materials have been considered an important source of natural products for human and animal health. Tea, only second to water, is the most consumed beverage in the world [10]. It contains a wide array of health promoting ingredients and consumption of tea has been shown to negate the negative impacts of stress [13], [14]. Moringa oleifera is well known for its many therapeutic, nutritional, and medicinal uses. Extracts (aqueous, hydroalcohol, or alcohol) made from M.oleifera leaves provide several health benefits including antioxidant, analgesic, antiulcer, antihypertensive, as well as tissue protective, radio protective, and immune modulating capacity (reviewed in [25]) and animal studies show that aqueous leaf extracts have a high degree of safety [26]. While the antistress potential of many other medicinal plants has been reported, to our knowledge the apoptogenic potential of Moringa has not been formally investigated [27-31]. The goal of this study was to examine the effect tea prepared from dried Morning leaves had on acute stress induced changes to blood circulating neutrophils and lymphocytes.

Here we show that mice that consumed Moringa tea for 4 days had no changes in the levels of circulating blood lymphocytes compared to the water group after $1 \mathrm{~h}$ or $12 \mathrm{~h}$ of restraint induced stress. Furthermore, we found no differences in the T cell or B cell lymphocyte subsets by flow cytometry. These data suggesting that Moringa tea may have no effect on lymphocytes are consistent with previous, unpublished 
data from our group showing no change in the percentage of lymphocytes ( $T$ or $B$ cells) within the spleen or lymph nodes of normal, healthy, unstressed mice after 5 days of Moringa tea consumption. In that study however, differences in $\mathrm{T}$ cell proliferative responses were detected, with the Moringa tea group having decreased proliferative responses after antiCD3 and anti-CD28 stimulation. It has been reported that restraining mice for one hour causes an increase in levels of neutrophils and a decrease in lymphocytes within the blood [4]. Additionally, during acute stress, T cells selectively redistributed into the skin, where they contribute to enhancement of the immune response [9]. Further studies therefore are needed to evaluate what effects Moringa tea has on lymphocyte trafficking (particularly to the skin). Also of interest is whether it alters lymphocyte activation and effector responses (cytokine and antibody production) in either normal or stressed conditions. Oyewo, et al report that wistar rats consuming aqueous Moringa leaf extracts for 56 days had significant increases in total white blood cell and lymphocyte counts but decreases in neutrophil counts [32]. Therefore, the effect that longer dosing with Moringa tea has on stress induced immunomodulation is relevant.

Stress has been shown to influence not only neutrophil levels but also function [33], [34]. Moringa consumption, in several animal studies, positively influences many neutrophil functions including oxidative burst, chemotaxis, adhesion, and phagocytosis [35-38]. In the current study, Moringa tea blocked the increase in blood circulating neutrophils that was expected to occur after 1 hour of restraint stress but led to significant increases in neutrophil levels after a longer period of stress (12h). But, the impact that consumption of Moringa tea has on neutrophil functions such as phagocytosis, adhesion and production of cytokines and other mediators during instances of stress remains to be determined. Additionally, the overall consequence of the immunomodulation by Moringa tea in instances of stress should be addressed. Are the decreases in neutrophil levels after consumption of Moringa tea during acute situations associated with positive health benefits or would it negatively impact innate immune protection during fight-or-flight situations? Moreover, would the increases in neutrophils during the longer period of stress (12h) in the lead to increased inflammation?

Depending on the type and duration, stress can modulate immune responses in either a positive or negative direction [4], [5], [39], [40]. The model used for this study used a onetime application of restraint stress (acute) and therefore the influence that Moringa tea consumption has on chronic immune modulation is yet to be determined. Furthermore, chronic psychological stress can also accelerate biological aging, and oxidative damage [39], [41]. Compared to the other parts of the plant (roots, stems, seeds, flowers and pods), extracts from the Moringa leaf have the greatest antioxidant activity [42]. Boiling Moringa leaves in water enhances aqueous antioxidant activity [43]. Suggesting that tea prepared from Moringa leaves could also protect from stress induced oxidative damage. Fernando et al investigating tea brewing extraction kinetics showed that antioxidant activity and composition of beneficial constituents such as phenolic compounds, caffeine and catechins are dependent on the method of preparation [44]. Thus, the optimal concentration and preparation (brewing time, water temperature) for maximum benefit of Moringa tea for stress immunomodulation as well as identifying the phytochemical components or antioxidants present in the brewed tea that are responsible for influencing immune cell function in instances of stress should be determined.

Conclusion: Stress can have negative consequences to an organism's health and overall well-being. Herbal medicine has long been recognized as a valuable and viable alternative to more conventional medical practices and consumption of medicinal plants that contain nutrients and phytochemicals that support the immune system or fight against diseases is practiced world-wide. Tea is a widely consumed beverage and represents an important source of nutritional and health benefits including impacts to immune cell function and stress. Moringa is an important plant commodity with great nutritional and medicinal potential. Uncovering more potential uses for Moringa and understanding the mechanisms for how it effects health promotion is important. This report is the first to investigate the immunomodulatory activity of $\mathrm{M}$. oleifera leaf tea during acute stress, demonstrate that it alters blood circulating neutrophils, and conclude that Moringa tea has adaptogenic capabilities in cases of stress.

\section{Acknowledgements and Conflict of Interest}

The researchers thank Mr. Livingston Mawutor of Winston-Salem, NC for growing and providing the Moringa leaves used in this study. We also acknowledge Dawn Conklin for technical assistance and Brian Sims for editorial comments. This work was completed by G.D. as partial requirement of a Master's Degree. This work was supported by grant number; NCX-270-5-12-120-1 (to R.C.M) from the USDA National Institute of Food and Agriculture. Its contents are solely the responsibility of the authors and do not necessarily represent the official views of the National Institute of Food and Agriculture. The authors report no conflict of interest.

\section{References}

1. Cohen S, Janicki-Deverts D, Doyle WJ, et al. Chronic stress, glucocorticoid receptor resistance, inflammation, and disease risk. Proceedings of the National Academy of Sciences. 2012; 109(16): 5995. doi: 10.1073/pnas.1118355109

2. Dhabhar FS. Acute stress enhances while chronic stress suppresses skin immunity. The role of stress hormones and leukocyte trafficking. Annals of the New York Academy of Sciences. 2000; 917: 876-893.

3. Segerstrom SC, Miller GE. Psychological Stress and the Human Immune System: A Meta-Analytic Study of 30 Years of Inquiry. Psychological bulletin. 2004; 130(4): 601-630. doi: 10.1037/0033-2909.130.4.601

4. Dhabhar FS. Enhancing versus Suppressive Effects of Stress on Immune Function: Implications for Immunoprotection versus Immunopathology. Allergy, Asthma, and Clinical Immunology: Official Journal of the Canadian Society of Allergy and Clinical Immunology. 2008; 4(1): 2-11. 
5. Dhabhar FS. Enhancing versus suppressive effects of stress on immune function: implications for immunoprotection and immunopathology. Neuroimmunomodulation. 2009; 16(5): 300-317. doi: 10.1159/000216188

6. Dhabhar FS. A hassle a day may keep the pathogens away: The fight-orflight stress response and the augmentation of immune function. Integrative and comparative biology. 2009; 49(3): 215-236. doi: 10.1093/icb/icp045

7. Yin D, Tuthill D, Mufson RA, Shi Y. Chronic Restraint Stress Promotes Lymphocyte Apoptosis by Modulating Cd95 Expression. The Journal of Experimental Medicine. 2000; 191(8): 1423-1428.

8. Zhang Y, Foster R, Sun X. Restraint Stress Induces Lymphocyte Reduction through p53 and PI3K/NF-KB Pathways. Journal of neuroimmunology. 2008; 200(1-2): 71-76. doi: 10.1016/j.jneuroim.2008.06.014

9. Dhabhar FS, McEwen BS. Acute stress enhances while chronic stress suppresses cell-mediated immunity in vivo: a potential role for leukocyte trafficking. Brain, behavior, and immunity. 1997; 11(4): 286-306. doi: 10.1006/brbi.1997.0508

10. inc. TAoTU. Tea Fact Sheet - 2018-2019. 2018; http://www.teausa. com/14655/tea-fact-sheet

11. Malongane F, McGaw $\sqcup$, Mudau FN. The synergistic potential of various teas, herbs and therapeutic drugs in health improvement: a review. J Sci Food Agric. 2017; 97(14): 4679-4689. doi: 10.1002/jsfa.8472

12. Butt MS, Sultan MT. Green tea: nature's defense against malignancies. Critical reviews in food science and nutrition. 2009; 49(5): 463-473. doi: $10.1080 / 10408390802145310$

13. Steptoe A, Gibson EL, Vuononvirta R. The effects of tea on psychophysiological stress responsivity and post-stress recovery: a randomised double-blind trial. Psychopharmacology. 2007; 190(1): 81-89. doi: 10.1007/s00213-006-0573-2

14. Hozawa A, Kuriyama S, Nakaya N. Green tea consumption is associated with lower psychological distress in a general population: the Ohsaki Cohort 2006 Study. The American journal of clinical nutrition. 2009; 90(5): 1390-1396. doi: 10.3945/ajen.2009.28214

15. Anwar F, Latif S, Ashraf M, Gilani AH. Moringa oleifera: a food plant with multiple medicinal uses. Phytotherapy research: PTR. 2007; 21(1): 17-25. doi: 10.1002/ptr.2023

16. Mbikay M. Therapeutic Potential of Moringa oleifera Leaves in Chronic Hyperglycemia and Dyslipidemia: A Review. Frontiers in Pharmacology. 2012; 3: 24. doi: 10.3389/fphar.2012.00024

17. Thurber MD, Fahey JW. Adoption of Moringa oleifera to combat under-nutrition viewed through the lens of the "Diffusion of innovations" theory. Ecology of food and nutrition. 2009; 48(3): 212-225. doi: 10.1080/03670240902794598

18. Abdull Razis AF, Ibrahim MD, Kntayya SB. Health benefits of Moringa oleifera. Asian Pacific journal of cancer prevention: APJCP. 2014; 15(20): 8571-8576

19. Kou X, Li B, Olayanju J, Drake J, Chen N. Nutraceutical or Pharmacological Potential of Moringa oleifera Lam. Nutrients. 2018; 10(3): 343. doi: $10.3390 /$ nu10030343

20. McKnight M, Allen J, Waterman JT, Hurley S, Idassi J, Minor RC, et al. Moringa tea blocks acute lung inflammation induced by swine confinement dust through a mechanism involving TNF-a expression, c-jun n-terminal kinase activation and neutrophil regulation. Am J Immunol. 2014; 10(2): 73-87.

21. Auwal M, Tijjani A, Sadiq M. Antibacterial and haematological activity of Moringa oleifera aqueous seed extract in Wistar albino rats. Sokoto Journal of Veterinary Sciences. 2013; 11(1).

22. Ajugwo AO, Mounbegna PE, Kemajou TS, Ofokansi VC. Effects of Moringa oleifera Leaves Extract on Haematological Parameters of Phenylhydrazine Anaemia Induced Wistar Rats. International Journal of Public Health and Safety. 2017; 2(4)

23. Gupta A, Gautam MK, Singh RK. Immunomodulatory effect of Moringa oleifera Lam. extract on cyclophosphamide induced toxicity in mice. Indian journal of experimental biology. 2010; 48(11): 1157-1160.

24. Corn Minor RA, Limmon GV, Miller-DeGraff $L$, et al. Double-Stranded RNA-Activated Protein Kinase Regulates Early Innate Immune Responses
During Respiratory Syncytial Virus Infection. Journal of Interferon \& Cytokine Research. 2010; 30(4): 263-272. doi: 10.1089/jir.2009.0051

25. Stohs SJ, Hartman MJ. Review of the Safety and Efficacy of Moringa oleifera. Phytotherapy research: PTR. 2015; 29(6): 796-804. doi: 10.1002/ptr.5325

26. Adedapo AA, Mogbojuri OM, Emikpe BO. Safety evaluations of the aqueous extract of the leaves of Moringa oleifera in rats. Journal of Medicinal Plants Research. 2009; 3(8): 586-591.

27. Bhattacharya SK, Muruganandam AV. Adaptogenic activity of Withania somnifera: an experimental study using a rat model of chronic stress. Pharmacology, biochemistry, and behavior. 2003; 75(3): 547-555. doi: 10.1016/S0091-3057(03)00110-2

28. Kenjale RD, Shah RK, Sathaye SS. Anti-stress and anti-oxidant effects of roots of Chlorophytum borivilianum (Santa Pau \& Fernandes). Indian journal of experimental biology. 2007; 45(11): 974-979.

29. Nagasirisha M, Mohamed Saleem TS. Effect of whole plant of Rostellularia diffusa Willd. on experimental stress in mice. Pharmacognosy Magazine. 2014; 10(3): 614-621. doi: 10.4103/0973-1296.139799

30. Srinivasan S, Loganathan S, Wankhar W, Rathinasamy S, Rajan R, et al. Stress effect on humoral and cell mediated immune response Indispensable part of corticosterone and cytokine in neutrophil function. Trials in Vaccinology. 2016; 5: 61-70. doi: 10.1016/j.trivac.2016.04.002

31. Nade VS, Yadav AV. Anti-stress effect of ethyl acetate soluble fraction of Morus alba in chronic restraint stress. Pharmaceutical biology. 2010; 48(9): 1038-1046. doi: 10.3109/13880200903473741

32. Oyewo EB, Adewale A, Ayoade AA, Akanji MA. Repeated Oral Administration of Aqueous Leaf Extract of Moringa oleifera modulated immunoactivities in Wistar Rats. Journal of Natural Sciences Research. 2013; 3(6)

33. Tsukamoto K, Machida K. Effects of life events and stress on neutrophil functions in elderly men. Immunity \& Ageing. 2012; 9(1): 13.

34. Tsukamoto K, Machida K. Effects of psychological stress on neutrophil phagocytosis and bactericidal activity in humans--a meta-analysis. International journal of psychophysiology: official journal of the International Organization of Psychophysiology. 2014; 91(2): 67-72.

35. Sudha P, Asdaq SM, Dhamingi SS, Chandrakala GK. Immunomodulatory activity of methanolic leaf extract of Moringa oleifera in animals. Indian journal of physiology and pharmacology. 2010; 54(2): 133-140.

36. Banji OJ, Banji D, Kavitha R. Immunomodulatory effects of alcbholic and hydroalcoholic extracts of Moringa olifera Lam leaves. Indian journal of experimental biology. 2012; 50(4): 270-276

37. Vongsak B, Sithisarn P, Gritsanapan W. Simultaneous HPLC quantitative analysis of active compounds in leaves of Moringa oleifera Lam. Journal of chromatographic science. 2014; 52(7): 641-645

38. NfambiJ, Bbosa GS, Sembajwe LF, GakungaJ, KasoloJN, etal.Immunomodulatory activity of methanolic leaf extract of Moringa oleifera in Wistar albino rats. Journal of basic and clinical physiology and pharmacology. 2015; 26(6): 603-611.

39. Aschbacher K, O'Donovan A, Wolkowitz OM, Dhabhar FS, Su Y, Epel E, et al. Good stress, bad stress and oxidative stress: insights from anticipatory cortisol reactivity. Psychoneuroendocrinology. 2013; 38(9): 1698-1708.

40. Campos AC, Fogaca MV, Aguiar DC, Guimaraes FS. Animal models of anxiety disorders and stress. Revista Brasileira de Psiquiatria. 2013; 35: 101-111.

41. Jorgensen A. Oxidatively generated DNA/RNA damage in psychological stress states. Danish medical journal. 2013; 60(7): B4685.

42. Shih M-C, Chang C-M, Kang S-M, Tsai M-L. Effect of Different Parts (Leaf Stem and Stalk) and Seasons (Summer and Winter) on the Chemical Compositions and Antioxidant Activity of Moringa oleifera. International journal of molecular sciences. 2011; 12(9): 6077-6088.

43. Yang R-Y, Tsou SCS, Lee T-C, Chang L-C, Kuo G, Lai P-Y, et al. Moringa, a Novel Plant Rich in Antioxidants, Bioavailable Iron, and Nutrients. In: Herbs: Challenges in Chemistry and Biology. American Chemical Society. 2006; 925: 224-239.

44. Fernando CD, Soysa P. Extraction Kinetics of phytochemicals and antioxidant activity during black tea (Camellia sinensis L) brewing Nutrition Journal. 2015; 14(1): 74. 